International Journal of Instruction e-ISSN: 1308-1470 • www.e-iji.net

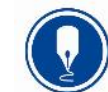

January $2022 \bullet$ Vol.15, No.1

p-ISSN: 1694-609X

pp. $509-526$

Article submission code:

20210310133336
Received: 10/03/2021

Revision: 11/07/2021
Accepted: 05/08/2021

OnlineFirst: 29/10/2021

\title{
Sketchnote and Working Memory to Improve Mathematical Word Problem Solving among Children with Dyscalculia
}

\section{Ayed H. Ziadat}

Dr., Department of Special Education, Princess Rahman College, Al-Balqa Applied University, Jordan, ayedziadat@bau.edu.jo

Dyscalculia presenting 3 to $6.5 \%$ of all those who need remediation in mathematics to enhance their ability of solving word problem. The study aimed to use sketchnote and working memory-based intervention to enhance word problem solving ability of students with dyscalculia. Thus, the study examined the role of integrated intervention involving both working memories training and using sketchnote technique. The intervention developed per recommendation of recent two themes of intervention, namely, schematic-based instruction and cognitive strategy. The study adopted an experimental group design with three groups, control, experimental (A), Experimental (B). The experimental group (A) engaged in the integrated intervention program, Experimental (B) engaged in sketchnote technique only. The study sample consists of 60 students presenting dyscalculia at third grade purposively selected and distributed equally among groups. The study adopted descriptive statistics, One Way ANCOVA test, Hoteling's Trace to validate study objectives. The analysis results show that the participants of group (A) gained the highest scores compared to other groups in word problem solving, the participants of group (B) exhibited significant difference in mathematical word follow-up test compared to the post-test scores and control group scores, and the integrated intervention program has a higher effect size on improving word mathematical problem solving of students presenting dyscalculia compared to training working memory only. The results implicated that it can be used integrated approaches to betterment the ability of students presenting dyscalculia of solving word problems.

Keywords: cognitive strategy, schematic-based instruction, sketchnote, student with dyscalculia, word problem solving, working memory

\section{INTRODUCTION}

Dyscalculia is a Greek-Latin phrase meaning a symptom. The primeval meaning of dyscalculia was blindless for numbers, which established enduring difficulties in calculating and exhibiting persistent numerical cognition deficits over the years, such as lack of symbolic processing. Dyscalculia is the smallest group under the umbrella of mathematical difficulties expressing 3 to $6.5 \%$ of all those who need remediation in

Citation: Ziadat, A. H. (2022). Sketchnote and working memory to improve mathematical word problem solving among children with dyscalculia. International Journal of Instruction, 15(1), 509526. https://doi.org/10.29333/iji.2022.15129a 
mathematics (Santos, 2021). Despite the small size of this group, it shares common attributes and characteristics, which need special settings to meet their learning needs. students presenting dyscalculia also have difficulty solving mathematical word problems (Jeya \& Albina, 2019). Other groups with mathematical difficulties have different various and diverge reasons of mathematical deficits, while students presenting dyscalculia usually share same attributes.

A plenty of research agreed that mathematic is necessary for success in daily life activities. Hence, relevant impairments negatively affecting an individual's quality of life in different scope; school life, career life, and social life (Fuchs, et al., 2020; Osman, et al., 2018; Monei \& Pedro, 2017; Csíkos, et al., 2012). Educators and psychologists consider word problem-solving as an indicator of employment and wages since it is standing on applying mathematics in everyday life (Fuchs, et al., 2020). Thus, there is perpetual attention driven toward remediation and intervention to reduce mathematical challenges and enhance mathematical skills to that presenting dyscalculia. According to Swanson et al. (2015) and Csíkos et al. (2012), word problem solving requires at least adequate levels of reading skills and working memory. Therefore, grade 3 is proposed as the optimal earliest grade for an intervention program to enhance word problem-solving. Therefore, the current study targets third-grade students.

There is an arguable debate that there are controversies in themes of word problemsolving interventions for students with a mathematical problem. Morin et al. (2017) established that the common two intervention themes are cognitive strategy instruction and schematic-based instruction. The current study agreed to both strategies theme; since working memory-enhancing considered as schematic-based instruction and sketchnote technique was classified as a cognitive strategy. A systematic review of the last primary school empirical-based intervention for students with dyscalculia proposed between 2004 to 2014 found that most of the proposed interventions were described as arithmetic interventions that rely on increasing students' numerical knowledge gains, utilizing arithmetic facts, mental calculation, and written calculation. Despite the effectiveness of these interventions, students exhibited resistance to engage interventions (Monei \& Pedro, 2017), in which it defined as a characteristic of students with dyscalculia and due to lack of students' interests and engaging in the intervention activities. Thus, the current study hypothesizes using sketchnote can attract students and increase their interest in the intervention.

The recommendation for intervention development for students presenting dyscalculia mainly concerned the presence of other combined deficits, either cognitive or neurodevelopmental disorders, such as dyslexia, because students with dyscalculia are more likely to have other associating deficit that may cause or effect mathematical ability of students (Santos, 2021). In the current study, the author adheres to these recommendations through a profound examination of participant's profiles and diagnostic reports. According to Monei and Pedro's (2017) review, the most effective interventions are those interventions based on student-centered approach, small group settings, and neuropsychological approaches. 
The present study contributes to providing an integrated intervention of both domains of the mathematical abilities model; specific skills and general skills, as argued by Traverso et al. (2021). The domain-specific skills are general numerical knowledge. While domain-general skills are the empowerment abilities to manipulate and utilizing knowledge that is directly associated with executive functions. In this study, the suggesting intervention proposes to enhance students' solving word problem ability by training working memory to activate students' numeral knowledge in which previous studies such as Friedman et al. (2018) found a high association between working memory and mathematical abilities development, while training on sketchnote is used for facilitating knowledge utilization and manipulating.

\section{Background}

\section{The Role of Working Memory}

Working memory can be defined as numerous components model of temporary storage, assimilation, preserving, retrieving, processing, manipulating, and developing prior knowledge. The working memory is controlling, observing, and demonstrating several aspects of both memory modalities, namely, phonological short-term memory and visuospatial short-term memory (Friedman, et al., 2018). Thus, training working memory promises to retrieve and manipulate prior mathematics knowledge gained by students for the sake of enhancing solving ability.

However, there is a plenty consensus on the association between dyscalculia and deficits in working memory and intellectual level (Fuchs, et al., 2020). Furthermore, recent empirical evidence estimated relation power between working memory and word problem-solving reached $r=0.7,0.53$, which indicates approximate high correlations (Fuchs, et al., 2020; Friedman, et al., 2018, respectively). Further meta-analysis study found that the type of mathematical difficulties moderates the relationship of working memory and mathematics performance, in which word problem solving estimated the large effect, in which the relationship was stronger for those presenting math disabilities compared to their normally developing peers (Friedman, et al., 2018). Put this in mind, working memory is not associated with language processing only, but it goes to stimulating attention to relevant information in a word problem and coordinating numerous involving cognitive resources (Fuchs, et al., 2020). Similar meta-analysis studies established that working memory is responsible for word problem differences among individuals, and the working memory has the highest effect on word problem solving compared to counterpart mathematical skills (Friedman, et al., 2018; Menon, 2016). However, the empirical result of previous studies empathized that working memory training enhances numeracy gain and mathematical performance of preschool children ( $d=0.8$; 1.16 respectively (large effect); (Passolunghi \& Costa, 2016)).

In this vein, there is strong evidence basis of assuming that developing working memory yields higher and advance word problem-solving skills. 


\section{The Role of Sketchnote}

Sketchnote is those sketches that students draw on their books or worksheets. In a more precise word, sketchnote is unconscious drawing in marginal note (Tadayon \& Afhami, 2017). Sketchnote is synonymous with taking visual notes. Sketchnote is about synthesizing learning, since it included acquiring new information, linking this information with prior knowledge, synthesizing new updated knowledge, and paraphrasing and summarizing it in the form of unconscious drawing notes (Weber, 2019). Sketchnote is a note-taking strategy that combined notes and drawing or simple strokes. Sketchnote is a mixed visual note that includes handwriting, drawings, typography, shapes, arrows, boxes, and lines (Fontecha, et al., 2018; Mendonça, 2016).

The paramount core of sketchnote is a free drawing and inducing a student-centered approach. The free drawing experience has a considerable huge effect size on word problem solving ( $d=0.62$, large effect; Csíkos et al., 2012). These effects can be explained through the significant relationship combined between sketching and math performance enhancement (Bakar, et al., 2016). The same study reported that children use sketching to represent their mathematical reasoning skills, comprehension, and acquisition concepts (Bakar, et al., 2016).

Sketching is considered a plausible strategy for enhancing word problem solving, since solving a word problem comprises a succeeding rational process starting from identifying a problem, interpreting requirements, electing an appropriate solving strategy, driven a solution, and justifying the answers. All these processes were sound complicated, but some students, particularly children, exhibit an instinct to draw and sketch pictures and symbols to solve the simplest problems. this small instinct of sketch countenances the thinking process (Bakar, et al., 2016; Saundry \& Nicol, 2006).

However, sketching not only affect the word problem-solving skills but also changes learners' attitudes and beliefs toward mathematics and engaging intervention (Morin, et al. 2017; Csíkos, et al., 2012), which is a great benefit since Fuchs et al. (2020) reported a resistance and refusal toward engaging intervention is the most hinder factor challenging intervention adoption. In line with using sketchnotes as a tool for maintaining learners' attention and focus, bringing joy in classrooms.

Nevertheless, the potential significance of sketchnote in academic practicing still unrevealed. The present study contributes to establishing launching points to explore and explicate the profound functions and benefits of using sketchnote in the academic practice.

\section{Study Objectives}

The study aims to assess the effectiveness of the intervention program in developing mathematical word problem-solving skills of students with dyscalculia. The intervention program is designed on two main approaches, namely enhancing working memory and sketchnote approach. Hence, the researcher hypothesizes that the intervention has a statistically significant effect on enhancing the skills of solving mathematical word problem of children with dyscalculia. 


\section{METHOD}

The study is a quasi-experimental study which rely on replacing randomizing technique with different controlling technique such as a counterbalanced design that utilized in this study (Fraenkel, et al., 2012). The approach adopted quantitative pre-post measurements and three groups design in order to assess the effectiveness of sketch-note and working memory-based intervention.

\section{Participants}

The sample comprises 60 male and female students in the third elementary grades aged 7-8 years old. All participants were selected purposively to ensure that are diagnosed with mathematical difficulties (dyscalculia) according to their student profiles. The participants were distributed into three groups: the experimental group (A), the experimental group (B), and the control group. The participants in the experimental group (A) engaged in both the sketchnote workshop and working memory-based training program. While participants in experimental group (B) exposed to sketchnote technique. Control group does not expose to any treatment, participants were taught using conventional strategies. All parents of children informed their consent prior the participation in the experiment.

\section{Measures}

\section{Math word Problem Solving test}

The author designed pre, post, and follow-up tests, each test consists of five wordproblems ( 2 points for each problem). Examiner gives a participant one point for correct mathematical expression and one mark for the correct final answer. Participants can accumulate 0 to 10 points in the test. The pre-test problems were related to the third unit in the governmental math book for 3rd grade, which was the "addition". The post-tests and follow-up problems were associated with the fourth unit in the same math book, which was the "subtraction".

Both tests were exposed to a panel of arbitrators, which comprises 10 academic and educational professionals. Arbitrators have extensive expertise in teaching disabled students and professionals in learning disabilities. Further, the validity and reliability of tests were calculated in a sample of 20 typically developing students in the 3rd grade. Cronbach alpha was $(0.68,0.71 ; 0.70)$ and Pearson coefficient of test-retest measurement was $(0.86,0.91,0.85)$ for pre, post, and follow up tests prospectively, which present good internal consistency, correlation, and reliability scores.

\section{Working Memory test}

The researcher used two primarily assessing tasks to evaluate working memory of young children, namely, keep track task and dual request selective task as developing by Traverso et al. (2021).

a) Keep Track Task 
To standardized "keep track" for the Arabic environments (Jordanian), the researcher translated tasks activities to Arabic language and applied tasks twice on the sample of 7 8 years old normally developing students $(n=70)$ over a period of 21 days. Task scores for the same sample are recorded. To assess the reliability of tasks, Pearson's correlation coefficient is extracted $(r=0.7)$, indicating acceptable and considerable reliability score.

These keep track tasks were conducted twice by participants at baseline and the end of the intervention program. Keep track tasks are based on exhibiting pictures series, four images in each series from around six categories: animals, fruit, buildings, clothes, professions, and vehicles. The author had symbolized each image with a distinct sign to facilitate retrieving pictures. The task repeated six-times at each measurement. The difficulty of tasks raises incrementally along with repetitions. For example, participants were asked to identify the images from one category in the same order they presented in the first trial. In the second, the participants were asked to identify the last picture from the dominant category exhibited in the series. In the latest three repetitions, the series comprised two designated categories, in which the participants were asked to identify the latest image from each group. During these trials, participants have to manage the interference among irrelative images. At the beginning of the last three repetitions, the examiner asked participants to pay attention to the nominated category or categories. Examiner gives participants one point (mark) for each correct answer without retrieving all pictures from the nominated category. If a participant answers correctly after reexposing images, he will gain a half-point (mark). This activity is conducted in 6 trials individually at each measurement. The highest grade is 9 , and the lower is zero.

b) Dual Request Selective Task

This task is designed to assess the information retention ability in working memory while performing a synchronized task. Various studies validated the psychometric properties of the task for young children (for example, Traverso, Tonizzi, Usai, \& Viterbori, 2021; De Franchis, Usai, Viterbori, \& Traverso, 2017; Lanfranchi \& Vianello, 2008) found that it is has acceptable to high psychometric properties. The task is performed in a repetition of 10. The participants have to fulfill two requirements in this task. First, clap their hand once the pointer reaches the red square. Second, keep in his mind the start points of the pointer (light pen). A square 4 X 4 (16 equivalent squares) chessboard was exposed to participants with a single red square. All squares in the chessboard have a number. For each trial, the examiner uses a light pen and slowly move on a specific path crossing the red square. Examiner selects the different paths with different start points and different lengths (2, 3, 4, 5, and 6 squares). The examiner starts with a simple path ( 2 squares length) and then increases the length of the path over repetition, in which 2 cases were tracked for each length. The participants get one point (mark) for each successful case (both requirements (clapping and retrieving start point) have to be achieved, if one of them was incorrect, the participant will miss the mark). A participant can accumulate 0 to 10 points in this task. Examiner assesses each participant individually with a noise distracted sound plays back. Further, the examiner practices the task before the first trials to guarantee participants' comprehending the task. 
To test the psychometric properties of the task, both Cronbach alpha and split-half coefficients were calculated in a sample of 63 typically developing children aged 7-8 years old. The Cronbach alpha was (0.84), and the split-half coefficient was (0.91).

\section{Intervention}

\section{Sketchnote workshop}

The workshop consists of four sessions (40 mins). Sessions were conducted on Saturday days in the school, which is a day off for students. The remedial teacher introduced the sketchnote technique in the first session and illustrated some relative symbols. In the second session, the teacher carries out examples of using sketchnote in various mathematics contexts mainly number knowledge, comparison, and numerical sequences. In the last two sessions, the teacher assigned various exercises to practice the sketchnote technique. The teacher stressed the base concept of sketchnote, which is the free drawing without any constraints to used specific symbols or texts. It is worth mentioning, 40 participants of experimental groups engaged to the sketchnote workshop.

\section{Working Memory-Based Training Program}

Training program consists of 16 sessions (30 mins). First two sessions are for social salutation between participants and their remedial mathematics teachers. In the succeeding sessions, remedial teachers introduce and train participants adopting numerous strategies for developing their working memory. In which one session is for introduction of strategy and the other session for training on applying strategy in mathematics context. Various strategies were taught in the program such as rehearsal strategy (using practice on the repeated basis to enhance memorizing; Friedman et al. (2018)), mental imagery (mentally sketching visual spatial components; Fuchs et al.(2020)), narrative strategy (using narrative technique to present information), visuospatial strategy(memorising abstract shapes), encoding strategy(construct memory indicators relevant to specific information), and grouping strategy (enhance collaborative activities between students)(Passolunghi \& Costa, 2016).

Training program started with the beginning of academic semester. In which two extra sessions per week were allocated for the training program. Training session conducted in source classrooms. Trained remedial teachers train and instruct participants through program. Author exposed the program both academic professionals and teachers in the capacity of teaching students with learning difficulties.

Only the participants of Experimental group (A) engaged to this training workshop.

\section{Procedure}

Figure no. (1) presents a visual presentation of study design and procedures. 


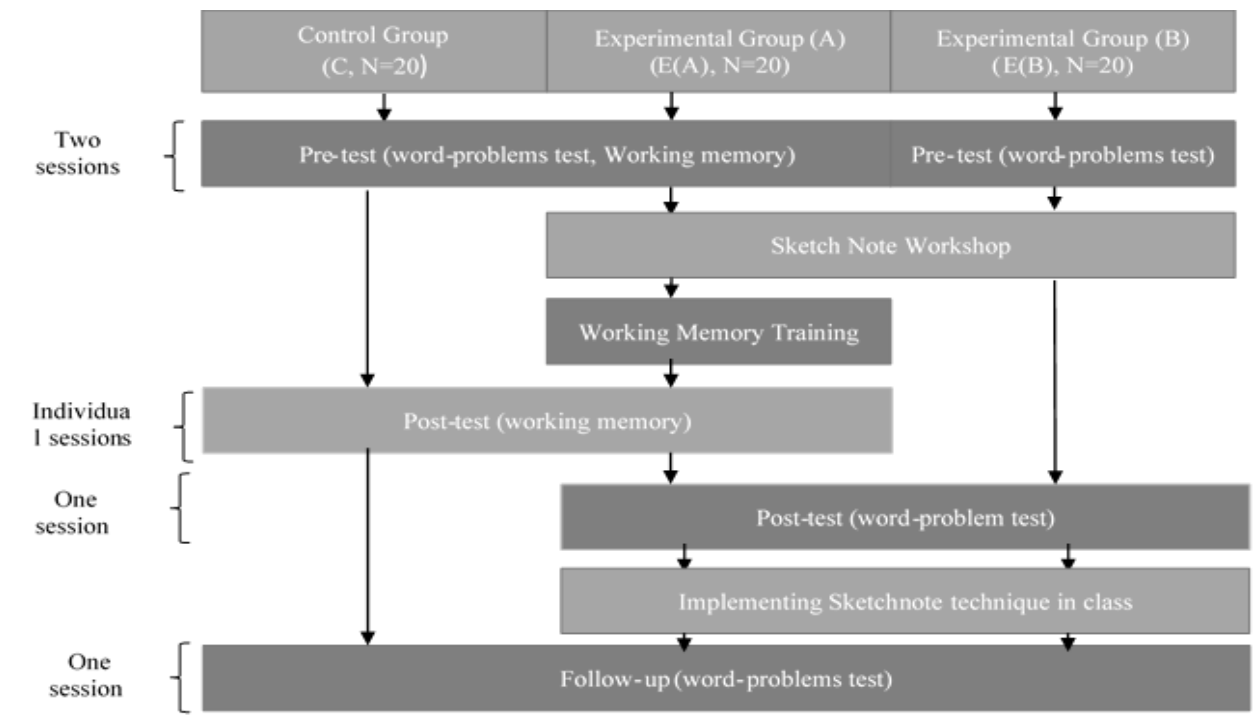

Figure 1

Experimental design of the study and associated procedures

The baseline phase is the first phase, which consists of two sessions in one week for premeasurement at the beginning of the semester. Both word-problems tests and working memory tests were administrated for each participant. Working memory tests were conducted individually, while a word problem test was conducted for all participants in one session.

The intervention phase is the longitude phase, in which both workshop and training program were conducted simultaneously. Two remedial teachers were recruited and trained to complete the training program and workshop. Both recruited teachers have at least a high diploma in learning disabilities and work in the capacity of source teacher for at least two practical experience years. Those qualified remedial teachers were selected purposively and recruited. The first remedial teacher is only trained to conduct a sketchnote workshop. As well the second is trained to conduct the training program. Both remedial teachers were naive to the study objectives and hypotheses to maintain outcomes' reliability and validity. Also, both teachers do not know each other.

Post phase is the second phase, which consists of two sessions in one week for measurement after the end training program. Follow up phase repeated both working memory test were re-administrated for both control and experimental group (A) participants and word problems test were re-administrated to participants in both experimental groups (A and B). Working memory tests were conducted individually, while a word problem test was conducted for targeted participants in one session.

Next post measurement phase, the first remedial teacher tutored participants of both experimental groups (A and B) "addition", the fourth unit in textbook, in different source classrooms, each group has its class. At the end of each lesson in the unit, the 
teacher asked students to summarize the lesson using sketchnote and solving one exercise at home.

The follow-up phase consists of one session in one week for follow-up-measurement after a period of one week from unit four ends, all participant in the three groups engaged a word problems follow-up test.

\section{Analysis technique}

The researchers used the succeeding statistical analysis techniques to statistically validate research finding:

- $\quad$ Means and Standard deviation.

- $\quad$ One Way ANOVA.

- $\quad$ Independent Sample T-test.

- $\quad$ Paired Sample T-test.

- $\quad$ One Way ANCOVA test.

- $\quad$ Pairwise Comparisons

\section{FINDINGS}

\section{Equivalence between Groups}

To assess equivalence among groups' participants in both working memory and word problem solving level, descriptive statistics and inferential statistics were used as following:

\section{Pre-Word Problem Test}

the study used One Way ANOVA test to show the significant mean score difference in pre math between groups at level of $\alpha \leq 0.05$ as following:

The results in table 1 showed that mean value for control group was (3.15), Experimental (A) (2.35), while the mean value for experimental (B) was (2.70). To show the statistical variance, the study used One Way ANOVA test as shown in table 2.

Table 1

Means and Standard deviations in pre math between groups

\begin{tabular}{llll}
\hline Group & $\mathrm{N}$ & Mean & Std. Deviation \\
\hline Control Group & 20 & 3.15 & 1.46 \\
\hline Experimental (A) & 20 & 2.35 & 1.18 \\
\hline Experimental (B) & 20 & 2.70 & 1.53 \\
\hline Total & 60 & 2.73 & 1.41 \\
\hline
\end{tabular}

Table 2

One way ANOVA

\begin{tabular}{llllll}
\hline & Sum of Squares & df & Mean Square & F & Sig. \\
\hline Between Groups & 6.433 & 2 & 3.217 & 1.647 & .202 \\
\hline Within Groups & 111.300 & 57 & 1.953 & & \\
\hline Total & 117.733 & 59 & & & \\
\hline
\end{tabular}

The result of the study confirmed that there were no statistically significant differences in pre math between group at the level of $\alpha \leq 0.05$ and this explains the equivalence among groups. 


\section{Pre-Working Memory Assessments}

The study used Independent Sample t-test to show the significant mean score difference in the Working Memory of students with dyscalculia among control and experimental group (A) in pre-test scores at the level of 0.05 as following:

Table 3

Independent sample T-test

\begin{tabular}{|c|c|c|c|c|c|c|}
\hline & $\mathrm{N}$ & Mean & Std. Deviation & t-value & df & Sig. \\
\hline \multirow{2}{*}{ group } & Pre- control 20 & 11.45 & 1.57 & 1.499 & 38 & 0.142 \\
\hline & Pre- $\operatorname{Exp}(\mathrm{A}) 20$ & 10.70 & 1.59 & 1.499 & 30 & 0.142 \\
\hline
\end{tabular}

The result as in table 3 showed that the two groups control and $\operatorname{Exp}(\mathrm{A})$ equivalence in the pre-test on the Working Memory of students with dyscalculia, the Means values were very closed and ( $\mathrm{t}$ calculated $=1.499)$ which is less than ( $\mathrm{t}$ tabulated $=1.96)$ and it is not significant at level of (0.05).

\section{The role of working memory training on working memory activation}

To validate the effectiveness of working memory training, scores both control and experimental group (A) in post-test were compared, as well as, the difference between pre and post-score of experimental groups (A) is detected.

The study used Independent Sample t-test to detect effectiveness of working memory training which looking at the significant mean score difference in in the Working Memory of students with dyscalculia among control and experimental group (A) in posttest scores at the level of 0.05 .

Table 4

Independent sample T-test

\begin{tabular}{|c|c|c|c|c|c|c|c|}
\hline & & $\mathrm{N}$ & Mean & Std. Deviation & t-value & df & Sig. \\
\hline \multirow[t]{2}{*}{ group } & Post control & 20 & 12.10 & 1.45 & & 38 & $<001 *$ \\
\hline & $\overline{\text { Post Exp (A) }}$ & 20 & 15.10 & 1.17 & -1.220 & 38 & $<.001 \%$ \\
\hline
\end{tabular}

*: Significant at level of $(0.05)$.

Table 4 results evidence that there is a significant mean score difference in in the post working memory test scores of students with dyscalculia among control and experimental group (A) and the score was higher for experimental group (A), while (tvalue $=-7.220$ ) which it is significant at the level of 0.05 . This result supports that training intervention is useful to activate students' working memory.

Paired sample t-test uses to show the significant mean score difference in the working memory of the experimental group(A) between pre and post-test measurements at the level of 0.05 as shown in table 5 below:

Table 5

Paired sample T-test

\begin{tabular}{llllllll}
\hline & & Mean & $\mathrm{N}$ & Std. Deviation & t-value & df & Sig. \\
\hline Exp group(A) & Pre & 10.70 & 20 & 1.59 & -17.963 & \multirow{2}{*}{19} & $<.001^{*}$ \\
\cline { 2 - 8 } & Post & 15.10 & 20 & 1.17 & & \\
\hline
\end{tabular}

*: Significant at level of (0.05). 
The working memory of students with dyscalculia in the post test was higher than the pre-test, which explains in the means values. Also, $t$ value $=-17.693$ and it is significant at level of (0.05) due to the role of working memory training program. Accordingly, it is validated that group(A) participants enhanced and trained their working memory.

\section{The effectiveness of intervention program}

A comparison conducted between experimental groups on both post and follow-up test. The differences in the post test reveal the effectiveness of working memory enhancing on solving word problem. Meanwhile, the comparison between experimental groups in follow up revealed the effectiveness of both work memory training and sketchnote techniques rather than using sketchnote only. These comparisons achieved using both descriptive, Hoteling's Trace, and One Way ANCOVA test.

Table 6

Descriptive statistics

\begin{tabular}{lllll}
\hline & group & Mean & Std. Deviation & $\mathrm{N}$ \\
\hline Math post & experimental (A) & 4.20 & 1.44 & 20 \\
\cline { 2 - 5 } & experimental (B) & 3.00 & 1.21 & 20 \\
\cline { 2 - 5 } Math followup & Total & 3.60 & 1.45 & 40 \\
\cline { 2 - 5 } & experimental (A) & 8.05 & 0.94 & 20 \\
\cline { 2 - 5 } & experimental (B) & 4.70 & 1.13 & 20 \\
\cline { 2 - 5 } & Total & 6.38 & 1.98 & 40
\end{tabular}

The descriptive statistics showed that mean value of the experimental group (A) in the post test math was (4.20) to be (8.05) in the follow-up, while the mean value of the experimental two group in the post test math was (3.00) to be (4.70) in the follow-up. This can be plausible since the group (A) participants engaged in two training activities (working memory and sketchnote), while the participants in the group (b) are only engaged in sketchnote training.

Difference in Mathematics score among groups

One Way ANCOVA test, Hoteling's Trace were used to show the statically significant differences as shown in table 7 below:

Table 7

One way ANCOVA test

\begin{tabular}{|c|c|c|c|c|c|c|c|}
\hline Source & $\begin{array}{l}\text { Dependent } \\
\text { Variable }\end{array}$ & $\begin{array}{l}\text { Type III Sum } \\
\text { of Squares }\end{array}$ & df & Mean Square & $\mathrm{F}$ & Sig. & $\begin{array}{l}\text { Partial Eta } \\
\text { Squared }\end{array}$ \\
\hline Group & Math post & 14.400 & 1 & 14.400 & 8.143 & $.007 *$ & .176 \\
\hline $\begin{array}{l}\text { Hoteling's Trace } \\
=2.787 \\
\text { Sig. }<.001 *\end{array}$ & Math follow & 112.225 & 1 & 112.225 & 103.634 & $<.001^{*}$ & .732 \\
\hline \multirow[t]{2}{*}{ Error } & Math post & 67.200 & 38 & 1.768 & & & \\
\hline & Math follow & 41.150 & 38 & 1.083 & & & \\
\hline \multirow[t]{2}{*}{ Total } & Math post & 600.000 & 40 & & & & \\
\hline & Math follow & 1779.000 & 40 & & & & \\
\hline \multirow[t]{2}{*}{ Corrected Total } & Math post & 81.600 & 39 & & & & \\
\hline & Math follow & 153.375 & 39 & & & & \\
\hline
\end{tabular}

*: significant at level of (0.05) 
The result showed that there is a significant mean score follow-up math among groups in post-test scores at the level of 0.05 , (F) value was of (8.143) for the group in the math post test score, and (F) value for the group was (103.634) in the math follow-up test score, the effect size $\left(\mathrm{Eta}^{2}\right)$ was $(17.6 \%)$, this explains that $(17.6 \%)$ from the improve mathematical word problem solving of children with dyscalculia due to the working memory training on the post test.

The effect size $\left(\mathrm{Eta}^{2}\right)$ value was (0.732) for the follow-up, this explains the working memory training and sketchnote based intervention program improve mathematical word problems solving of children with dyscalculia with $(73.2 \%)$ on the follow up measurement.

Thus, it is obvious that the combination of working memory and sketchnote induce highest betterment than working memory training-based intervention only. However, to statistically validate this conclusion, the study compared between effect sizes due the groups to identify which group benefited from the intervention as shown in table 8 .

Table 8

Pairwise comparisons

\begin{tabular}{lllll}
\hline Dependent Variable & (I) group & (J) group & Mean Difference (I-J) & Sig. $^{\text {b }}$ \\
\hline Math post & experimental (A) & experimental (B) & $1.200^{*}$ & .007 \\
\hline Math follow-up & experimental (B) & experimental (A) & $-1.200^{*}$ & .007 \\
\hline & experimental (A) & experimental (B) & $3.350^{*}$ & $<.001^{*}$ \\
\hline
\end{tabular}

The result showed that there were statistically significant differences in the effect size, and the variance was in favour of group (Experimental (A)) in the post and follow-up measurement.

Furthermore, a comparison between pre and follow up of group (A) to advance the effectiveness of integrated interventions rather than sketchnote only. The study used the descriptive statistics, Hoteling's Trace and One Way ANCOVA test to show the significant mean score difference pre and follow-test math among both experimental groups $(\exp A, \exp B)$ at the level of 0.05 .

Table 9

Descriptive statistics

\begin{tabular}{lllll}
\hline & group & Mean & Std. Deviation & $\mathrm{N}$ \\
\hline \multirow{2}{*}{ Math pre } & experimental A & 2.35 & 1.18 & 20 \\
\cline { 2 - 5 } & experimental B & 2.70 & 1.53 & 20 \\
\cline { 2 - 5 } & Total & 2.53 & 1.36 & 40 \\
\hline Math follow & experimental A & 8.05 & 0.94 & 20 \\
\cline { 2 - 5 } & experimental B & 4.70 & 1.13 & 20 \\
\cline { 2 - 5 } & Total & 6.38 & 1.98 & 40 \\
\hline
\end{tabular}

The descriptive statistics showed that mean value for the experimental group (A) in the pre-test math was (2.35) to be (8.05) in the follow-up, while the mean value of the experimental group (B) in the pre-test math was (2.70) to be (4.70) in the follow-up.

One Way ANCOVA test, Hoteling's Trace were used to show the statically significant differences as shown in table 10 below: 
Table 10

One way ANCOVA test

\begin{tabular}{|c|c|c|c|c|c|c|c|}
\hline Source & $\begin{array}{l}\text { Dependent } \\
\text { Variable }\end{array}$ & $\begin{array}{l}\text { Type III Sum } \\
\text { of Squares }\end{array}$ & df & Mean Square & $\mathrm{F}$ & Sig. & $\begin{array}{l}\text { Partial Eta } \\
\text { Squared }\end{array}$ \\
\hline Group & Math pre & 1.225 & 1 & 1.225 & .658 & .422 & .017 \\
\hline $\begin{array}{l}\text { Hoteling's Trace }=3.299 \\
\text { Sig. }<.001 *\end{array}$ & Math follow & 112.225 & 1 & 112.225 & 103.634 & $<.001 *$ & .732 \\
\hline \multirow[t]{2}{*}{ Error } & Math pre & 70.750 & 38 & 1.862 & & & \\
\hline & Math follow & 41.150 & 38 & 1.083 & & & \\
\hline \multirow[t]{2}{*}{ Total } & Math pre & 327.000 & 40 & & & & \\
\hline & Math follow & 1779.000 & 40 & & & & \\
\hline \multirow[t]{2}{*}{ Corrected Total } & Math pre & 71.975 & 39 & & & & \\
\hline & Math follow & 153.375 & 39 & & & & \\
\hline
\end{tabular}

*: significant at level of $(0.05)$

The result showed that there is a significant mean score follow-up math among groups in pre-test scores at the level of 0.05 just for math follow-up, (F) value was of (103.634), and the effect size $\left(\mathrm{Eta}^{2}\right)$ value was $(0.732)$ for the follow-up, this explains the working memory and sketchnote based interventions improve mathematical word problems solving of children with dyscalculia with (73.2\%) on the follow up measurement. While there are no statistically significant differences in the pre-math $(F)$ value was of (0.658) and it is not significant at level of (0.05).

Accordingly, the working memory training is responsible of $17.6 \%$ of improvement in word problem solving problem, while the improvement increased to reach $73.2 \%$ when both sketchnote and working memory integrated in one intervention. Thus, the study hypothesis is accepted.

The study compared between effect sizes due the groups to identify which group benefited from the intervention as shown in table 11 .

Table 11

Pairwise comparisons

\begin{tabular}{lllll}
\hline \multirow{2}{*}{ Dependent Variable } & (I) group & (J) group & $\begin{array}{l}\text { Mean Difference } \\
\text { (I-J) }\end{array}$ & \\
& & & Sig. \\
\hline Math pre & experimental (A) & experimental (B) & -.350 & .422 \\
\hline Math follow & experimental (B) & experimental (A) & .350 & .422 \\
\hline & experimental (A) & experimental (B) & $3.350^{*}$ & $<.001^{*}$ \\
\hline
\end{tabular}

The result showed that there were statistically significant differences in the effect size, and the variance was in favour of group (Experimental A) in the follow-up measurement and there were no statistically significant differences in the effect size regarding to pre math.

However, to validate that the integrated intervention is better than betterment of each working memory and sketchnote only. The study used paired sample t-test to show the variance between the pre and post math test on the exp group(A) and the variance between post and follow-up math test on the exp group (B) as shown in table 12 below 
Table 12

Paired sample T-test

\begin{tabular}{|c|c|c|c|c|c|c|c|}
\hline & & Mean & $\mathrm{N}$ & Std. Deviation & t-value & $\mathrm{df}$ & Sig. \\
\hline Exp & Math pre & 2.35 & 20 & 1.18 & \multirow[b]{2}{*}{-6.749} & \multirow[b]{2}{*}{19} & \multirow[b]{2}{*}{$<.001 *$} \\
\hline $\begin{array}{l}\text { Group } \\
\text { (A) }\end{array}$ & Math post & 4.20 & 20 & 1.44 & & & \\
\hline$\overline{\operatorname{Exp}}$ & Math post & 3.00 & 20 & 1.21 & \multirow[b]{2}{*}{-5.508} & \multirow[b]{2}{*}{19} & \multirow[b]{2}{*}{$<.001 *$} \\
\hline $\begin{array}{l}\text { Group } \\
\text { (B) }\end{array}$ & $\begin{array}{l}\text { Math } \\
\text { Follow-up }\end{array}$ & 4.70 & 20 & 1.13 & & & \\
\hline
\end{tabular}

*: Significant at level of (0.05).

The result showed that there were a statistically significant differences between Pre and post-test math among exp group(A) ( $\mathrm{t}=-6.749)$ and it is significant at level of (0.05), on the other hand there were a statistically significant differences between Post and followup test math among exp group(B) $(\mathrm{t}=-5.508)$ and its significant at level of (0.05).

Furthermore, to validate that the integrated intervention improved the ability of targeted students to solve word problem, their performance was compared to scores of the control group participants who are taught by regular instruction. The study used Independent Sample T-test to show the significant mean score difference in the followup scores of students with dyscalculia between control and group (A) at the level of 0.05 as following:

Table 13

Independent sample T-test

\begin{tabular}{llllllll}
\hline & & $\mathrm{N}$ & Mean & Std. Deviation & t-value & Df & Sig. \\
\hline Math & Control & 2 & 4.05 & 1.28 & \multirow{2}{*}{$-11.266-$} & 38 & $<.001^{*}$ \\
\cline { 2 - 8 } Follow & Exp (A) & 2 & 8.05 & 0.94 & & \\
\hline
\end{tabular}

*: Significant at level of 0.05

The result as in table 13 showed that there were statistically significant differences in the follow-up scores between control and group (A), the mean value of the control group was (4.05), corresponding to (8.05) for the group $(\mathrm{A})$, ( $\mathrm{t}$ calculated $=-11.266)$ which is more than $(t$ tabulated $=1.96)$ and it is significant at level of $(0.05)$ and the variance was in favour of group (A). Accordingly, it is true to say that group(A) outperformed control group due to the treatment they received.

Sum all together, the hypothesis that the intervention has a statistically significant effect on enhancing the skills of solving mathematical word problem of children with dyscalculia is accepted.

\section{DISCUSSION}

The result of analysis shows that working memory training contribute to $17.6 \%$ improvement of mathematical word problem solving ability of children with dyscalculia. That accords with recent empirical evidence estimated relation power between working memory and world problem-solving reach $\mathrm{r}=0.53$ (large effect) (Friedman, et al., 2018; 0.7 Fuchs, et al. 2020; Menon, 2016) since the working memory enhancement stimulating attention to relevant information in a word problem and coordinating numerous involving cognitive resources as well as language processing. Furthermore, 
the results found plausible in the term of the empirical result of previous studies empathized that working memory training enhances numeracy gain and mathematical performance of preschool children $(\mathrm{d}=0.8 ; 1.16$ respectively (large effect); (Passolunghi \& Costa, 2016)).

The results also showed that sketchnote only improve students' ability of solving word problem significantly since the differences between pre and follow-up score of group (B) are significant. This agreed to previous studies that sketchnote has considerable effect size on word problem solving ( $\mathrm{d}=0.62$, large effect; Csíkos, et al., 2012) accords to Bakar et al. (2016) reporting the significant relationship combined between sketching and math performance enhancement and observed that children use sketching to represent their mathematical reasoning skills, comprehension, and acquisition concepts. This result is also expected and plausible because solving a word problem comprises a succeeding rational process starting from identifying a problem, interpreting requirements, electing an appropriate solving strategy, driven a solution, and justifying the answers. In which children exhibit instinct tends to use pictures and symbols to simplify the problem components and accommodates their thinking process (Bakar, et al., 2016; Saundry \& Nicol, 2006).

Furthermore, sketching not only affect the word problem-solving skills but also changes learners' attitudes and beliefs toward mathematics and engaging intervention (Morin, et al. 2017; Csíkos, et al., 2012).

The result, furthermore, supported the theoretical expectation of the effectiveness of using both sketchnote and training memory to substantially enhance the ability of solving word problems. The result supports that both working memory training and sketchnote improve mathematical word problems solving of children with dyscalculia with $73.2 \%$. Moreover, the students who received sketchnote and working memory trainings outperformed both students who received sketchnote training only and students who received conventional instruction. Not surprising that sketchnote advances the impact of working memory, since sketchnote technique accords children instinct exhibits of drawing and sketching pictures and symbols to solve the simplest problems. This small instinct of sketch countenances the thinking process (Bakar, et al., 2016; Saundry $\&$ Nicol, 2006). Furthermore, sketcnote may eliminate negative attitudes and beliefs of children toward word problem solving as explained by (Morin, et al. 2017; Csíkos, et al., 2012). Taking in consideration, children with dyscalculia has a trait of resistance intervention as reported by (Fuchs, et al. 2020; Monei \& Pedro, 2017). Hence, the sketchnote took a role to eliminate such attitudes.

According to the benefits of cognitive strategy instruction and schematic-based instruction. The sketchnote training is a cognitive instruction that developing thinking process in a managed manner and flexible learning mode, while the working memory training as schematic instruction facilitating thinking skills developing by identifying underlying information and interoperating information.

Thus, it is obvious that the integration between working memory training and sketchnote induce highest betterment than working memory training-based intervention only or skectnote training only. This result contributes providing benefits of integrating multiple 
interventions approach to integrate each other in order to enhance the ability of students presenting dyscalculia in mathematics.

\section{CONCLUSION}

The study examined the role of integrated intervention involving both working memories developing and using sketchnote technique. The study adopted an experimental group design with three groups, control, experimental (A), Experimental (B). The experimental group (A) engaged in the integrated intervention program, while, experimental (B) engaged in sketchnote technique only. The study sample consists of 60 students presenting dyscalculia in third grade. The analysis results show that working memory training contributes to $17.6 \%$ improvement of mathematical word problem solving ability, while the integrated intervention program has a higher effect size on improving word mathematical problem solving of students presenting dyscalculia reached $73.2 \%$ of enhancement. Hence, the researcher validated and accepted the hypothesis that the intervention has a statistically significant effect on enhancing the skills of solving mathematical word problem of children with dyscalculia. The study results agreed to previous studies in working memory found a large considerable effect of the intervention on word problem solving of students with dyscalculia. Sketchnote using alongside enhancing working memory advances the effect of last mentioned, and it is accommodating the instinctive nature of children to draw. Furthermore, the effect can be explained by the role of sketchnote reducing negative attitudes and beliefs of children and increase their engagement and motivation.

The presented study was conducted using participants in the same age group and from the same background (Arabs). Accordingly, the results may not be valid or generalisable to students with different age groups or from a different background (foreign children). Furthermore, the present study does not examine the effect of intervention among different levels of deficits (severity of deficit) since the Jordanian diagnose checklist does not rely on a specific international or unified scale for the deficit, as per the researcher's best knowledge and observed from students' profiles. Similar to the mathematics subject, the present study only conducted the "addition" subject from math textbooks, thus, the results of the study cannot validate for all mathematics subjects. Accordingly, future research can examine the effectiveness of intervention across different mathematics subjects, such as counting, geometric shapes, and so forth.

Further studies can use a questionnaire to examines children's attitudes, beliefs, and motivation to use sketchnote approach in solving word problems, and the responsible change by intervention in children's perception toward learning math. Future studies can assess the reducing role of sketchnote to student's resistance attitudes and tier perceived perception toward mathematics and engaging intervention. Also, incoming research can reserve children drawing and analyse their reasoning, comprehension, and acquisition concepts, which benefits revealing misconception in math, their way of analysing the problem, and their learning gains.

Future studies recommended to assess the implementation facility of this strategy in any school or teaching settings such as inclusion class, special education classrooms, or source classrooms, and either for individual or large groups. 


\section{REFERENCES}

Bakar, K. A., Way, J., \& Bobis, J. (2016). Young Children's Drawings in Problem Solving. In B. White, M. Chinnappan, \& S. Trenholm, Opening up mathematics education research (Proceedings of the 39th annual conference of the Mathematics Education Research Group of Australasia) (pp. 86-93). MERGA.

Csíkos, C., Szitányi, J., \& Kelemen, R. (2012). The effects of using drawings in developing young children's mathematical word problem solving: A design experiment with third-grade Hungarian students. Educational Studies in Mathematics, 81, 47-65. https://doi.org/10.1007/s10649-011-9360-z.

De Franchis, V., Usai, M. C., Viterbori, P., \& Traverso, L. (2017). Preschool executive functioning and literacy achievement in Grades 1 and 3 of primary school: A longitudinal study. Learning and Individual Differences, 54(2017), 184-195. https://doi.org/10.1016/j.lindif.2017.01.026.

Fontecha, A. F., O'halloran, K. L., Tan, S. n., \& Wignell, P. e. (2018). A multimodal approach to visual thinking: the scientific Sketchnote. Visual Communication, 18(1), 529. https://doi.org/10.1177/1470357218759808

Fraenkel, J., Wallen, N., \& Hyun, H. (2012). How to Design and Evalute Research in Education. NewYork: The McGrew-Hill.

Friedman, L. M., Rapport, M. D., Orban, S. A., Eckrich, S. J., \& Calub, C. A. (2018). Applied Problem Solving in Children with ADHD: The Mediating Roles of Working Memory and Mathematical Calculation. Journal of Abnormal Child Psychology, 46(3), 491-504. https://doi.org/10.1007/s10802-017-0312-7

Fuchs, L., Fuchs, D., Seethaler, P. M., \& Barnes, M. A. (2020). Addressing the role of working memory in mathematical word-problem solving when designing intervention for struggling learners. ZDM - Mathematics Education, 52, 87-96. https://doi.org/10.1007/s11858-019-01070-8.

Jeya, A., \& Albina, D. (2019). A Study of Students with Dyscalculia and Their Mathematical Abilities at Primary Schools in Karaikudi. PEOPLE: International $\begin{array}{llll}\text { Journal Of Social } & \text { Sciences, 4(3), } & \text { 1533-1542. }\end{array}$ https://doi.org/10.20319/pijss.2019.43.15331542

Lanfranchi, S., \& Vianello, R. (2008). A battery for assessing short-term and working memory in preschoolers: Preliminary results. In N. B. Johansen, New research on shortterm memory. NY: Nova Science Publishers.

Mendonça, P. (2016). Graphic facilitation, sketchnoting, journalism and 'The Doodle Revolution': New dimensions in comics scholarship. Studies in Comics, 7(1), 127-152. https://doi.org/10.1386/stic.7.1.127_1

Menon, V. (2016). Working memory in children's math learning and its disruption in dyscalculia. Current Opinion in Behavioral Sciences, 10, 125-132. https://doi.org/10.1016/j.cobeha.2016.05.014 
Monei, T., \& Pedro, A. (2017). A systematic review of interventions for children presenting with dyscalculia in primary schools. Educational Psychology in Practice, 33(3). https://doi.org/10.1080/02667363.2017.1289076

Morin, L. L., Watson, S. M., Hester, P., \& Raver, S. (2017). The Use of a Bar Model Drawing to Teach Word Problem Solving to Students with Mathematics Difficulties. Learning Disability Quarterly, 40(2), 91-104. https://doi.org/10.1177/0731948717690116

Osman, S., Yang, C. N., Abu, M. S., Ismail, N., Jambari, H., \& Kumar, J. A. (2018). Enhancing Students' Mathematical Problem-Solving Skills through Bar Model Visualisation Technique. International Electronic Journal of Mathematics Education, 13(3), 273-279. https://doi.org/10.12973/iejme/3919

Passolunghi, M. C., \& Costa, H. M. (2016). Working memory and early numeracy training in preschool children. Child Neuropsychology, 22(1), 81-98. https://doi.org/10.1080/09297049.2014.971726

Santos, F. H. (2021). Intervention for children with developmental dyscalculia. In D. Lucangeli, Understanding Dyscalculia: A guide to symptoms, management, and treatment (pp. 65-93). NY: Routledge.

Saundry, C., \& Nicol, C. (2006). Drawing as problem-solving: Young children's mathematical reasoning through pictures. Proceedings 30th Conference of the International Group for the Psychology of Mathematics Education (pp. 57-63). Prague: PME.

Swanson, H. L., Lussier, C. M., \& Michael J. Orosco. (2015). Cognitive Strategies, Working Memory, and Growth in Word Problem Solving in Children with Math Difficulties. Journal of Learning Disabilities, 48(4), 339-358. https://doi.org/10.1177/0022219413498771

Tadayon, M., \& Afhami, R. (2017). Doodling Effects on Junior High School Students' Learning. The International Journal of Art \& Design Education, 36(1), 118-125. https://doi.org/10.1111/jade.12081

Traverso, L., Tonizzi, I., Usai, M. C., \& Viterbori, P. (2021). The relationship of working memory and inhibition with different number knowledge skills in preschool children. Journal of Experimental Child Psychology, 203(2021), 1-21. https://doi.org/10.1016/j.jecp.2020.105014

Weber, H. (2019). Stances, Signposts, and Sketchnotes: Approaches for Active Engagement with Content. Ohio Journal of English Language Arts, 59(1), 25-29. $\begin{array}{llll}\text { Retrieved } & 5 & \text { March, } & 2021\end{array}$ https://web.a.ebscohost.com/abstract?direct=true \&profile=ehost\&scope=site \&authtype= crawler\&jrnl=10852492\&AN=144793279\&h=O9Tavw9NIow6FuRxUDpj4zdP0Jgob5 TvhhQ1O7rthnRnYpb0yfjyeSgPaN5ratSmopIJYIrMYhBAUagF7RE6gw\%3d\%3d\&crl= c\&resultNs $=$ AdminWebAuth\&resultLocal $=$ Er 